\title{
Correction to: Qualitative description of the submission and agonistic behavior of the Spix's Macaw (Cyanopsitta spixii, Wagler 1832), with special reference to the displacement displays
}

\author{
Vladislav Marcuk $^{1}$ (D) Cromwell Purchase $^{1} \cdot$ Donovan de Boer $^{1} \cdot$ Marcellus Bürkle $^{2} \cdot$ Katrin Scholtyssek $^{1}$
}

Published online: 3 August 2020

(C) Japan Ethological Society 2020

\section{Correction to: Journal of Ethology \\ https://doi.org/10.1007/s10164-020-00650-6}

Unfortunately, in the publication title of the online first version (published on the 03.06.2020) of the article the author name of the primal describer for the Spix's Macaw is incorrectly stated as Spix 1824. The name and date should be correctly given as Wagler 1832 . The authors apologize for the inconvenience caused.

Publisher's Note Springer Nature remains neutral with regard to jurisdictional claims in published maps and institutional affiliations.

The original article can be found online at https://doi.org/10.1007/ s10164-020-00650-6.

Vladislav Marcuk

vladislav.marcuk@googlemail.com

1 Association for the Conservation of Threatened Parrots e. V., Hindenburgstraße 37, Hannover, Germany

2 Tierarztpraxis Dr. Bürkle, Eisenbahnstraße 32, 77855 Achern, Germany 